\title{
PERSEPSI MASYARAKAT TERHADAP ISU PAJAK LINGKUNGAN DI KABUPATEN KEPULAUAN SIAU TAGULANDANG BIARO (SITARO)
}

\author{
CELLINIA TUTER \\ Sekolah Pascasarjana Fakultas Ekonomi dan Bisnis Universitas Airlangga \\ Email: celliniatuter@yandex.com
}

ARTICLE HISTORY

Received:

1 Februari 2020

Revised

3 March 2020

Accepted:

19 March 2020

Online available:

9 Mei 2020

Keywords:

Perception,

Environmental Tax,

\section{ABSTRACT}

This study aims to enrich the literature on public policy, especially tax policy environment is important to protect the natural kseimbangan and to contribute to the government about how this environmental tax policy should be implemented in the future with regard to the interests of local communities are far remote.

This study used a qualitative approach to the sources of data used are primary data in the form of interviews with stakeholders, such as governments, small businesses, and the general public and secondary data such as library materials, such as laws and regulations on environmental taxes. Objects in this study is Sitaro Islands Regency (Sitaro).

The results of this study indicate that the level of awareness of the various parties in Sitaro Islands District is still lacking; There are three areas that must be considered government in formulating tax policy environment that is the process of establishing an environmental tax policy, the imposition of environmental tax rate basis and management of environmental taxes; Environmental taxes can serve as regulatory functions and functions budgetair; Public perceptions of the environmental tax is the first goal for the interest in protecting the environment from pollution and the second is to increase government revenue; The local government is considered more appropriate in determining the environmental tax policy than the central government since the area is more aware of the conditions of their respective regions; Environmental taxes can be applied as long as proportionally; Sitaro Islands District which is a remote area already requires an environmental tax for air pollution that is currently underway and is used to protect the local ecosystem. 


\section{LATAR BELAKANG}

Lingkungan hidup sebagai media hubungan timbal balik antara makhluk hidup dengan unsur alam yang menjadi suatu kesatuan yang dapat menentukan daya dukung lingkungan hidup terhadap pembangunan. Fenomena yang sering terjadi dimana manusia secara membabibuta mengeksploitasi lingkungan hidup sesuai keinginannya, tanpa menghiraukan dampak buruk yang ditimbulkan akibat aktivitas yang dilakukannya.

Sulawesi Utara salah satu contohnya, seperti daerah lainnya di Indonesia, juga kaya akan potensi alamnya. Kerusakan lingkungan yang terjadi akibat pengelolaan hasil alam terjadi juga di daerah ini. Salah satunya adalah pencemaran air laut dan biotanya yang disebabkan oleh PT. Newmont Minahasa Raya (PT.NMR) yang bergerak di industri tambang. Perusahaan ini melakukan aktivitas operasional dengan membuang limbah kotor ke teluk buyat sehingga merusak ekologi dan kelangsungan hidup masyarakat sekitar Teluk Buyat. Dampak dari kasus Teluk Buyat ini tidak hanya tercemar di sekitar Kabupaten Minahasa, tetapi menyebar di beberapa daerah di Sulawesi Utara, seperti di Kabupaten Bolaang Mongondow, Minahasa Selatan, dan Ratotok (Kumurur, 2006).

Dengan adanya permasalahan lingkungan hidup yang timbul di muka bumi ini, menyebabkan diperlukannya suatu kebijakan yang dapat digunakan untuk mengatasi kerusakan lingkungan yang terjadi. Salah satu bentuk dari pengelolaan lingkungan hidup adalah dengan menaati peraturan perundang-undangan di bidang lingkungan hidup. Hal ini sesuai dengan pengertian pajak lingkungan yaitu merupakan pungutan yang bersifat insentif permanen yang bertujuan mengurangi pencemaran dan menekan biaya penanggulangannya (Hardjasoemantri, 2005).

Namun penerapan terhadap pajak lingkungan di Indonesia hingga tahun 2014 masih belum memiliki kepastian dalam pelaksanaannya. Pungutan pajak lingkungan rencananya akan dituangkan dalam Undang-Undang Pajak Daerah dan Retribusi Daerah (UU PDRD). Rancangan Undang-Undang tersebut mengusulkan akan ditetapkan pajak lingkungan dengan tarif sebesar $0,5 \%$ dari biaya produksi total perusahaan yang aktivitas operasionalnya mencemari lingkungan (Abdullah, 2009). Pajak sebesar itu rencananya akan dikenakan kepada perusahaan manufaktur dengan nilai produksi di atas Rp 300 juta per tahun. Walaupun demikian, usulan pajak lingkungan dalam rancangan undangundang Pajak Daerah dan Retribusi Daerah tersebut ditolak oleh Dewan Perwakilan Rakyat (Haryadi, 2006).

Bagaimana persepsi masyarakat terhadap pajak lingkungan menjadi fokus dalam penelitian ini. Daerah yang menjadi subjek penelitian ini adalah masyarakat di salah satu daerah di Sulawesi Utara yaitu Kabupaten Kepulauan Siau Tagulandang Biaro (Sitaro) yang terletak di ujung utara propinsi Sulawesi Utara. Perekonomian Kabupaten

Kepulauan Siau Tagulandang Biaro didominasi oleh sektor perdagangan yang 
mengandalkan komoditas andalan daerah ini, baik di bidang pertanian, perkebunan maupun perikanan dan kelautan serta sektor wisata maritim dan bahari.

Permasalahan lingkungan sekarang menjadi isu pentingan bagi kabupaten ini. Mulai dari bencana banjir dan puting beliung yang merusakkan beberapa kampong di tahun 2014 serta problem sampah. Air minum juga menjadi problem utama karena kabupaten ini yang terdiri dari 47 pulau kecil ini dikelilingi oleh laut yang luas dan air minum tergantung dari sungai yang sudah mengalami sedimentasi dan tercemar. Salah satu daerah di kabupaten ini yaitu Ulu, mengalami permasalahan penyediaan air minum karena sumber air baku yang digunakan untuk pengolahan air sudah mulai tercemar akibat aktivitas tambang inkonvensional sehingga menyebabkan air baku menjadi keruh. Di Kabupaten kepulauan Siau Tagulandang Biaro juga terdapat industri kecil rumah tangga seperti industri tempe, tahu dan rumah makan yang menghasilkan limbah.

Dengan demikian kabupaten Sitaro yang merupakan kepulauan terkecil sangat menggantungkan hidup masyarakatnya dengan kondisi alam dan lingkungannya. Jika udara, tanah dan air yang disana tercemar maka sangat sulit bagi kapubaten yang berbentuk kepulauan kecil ini untuk mempertahankan ekonomi dan hidupnya.

Untuk itu perlu diketahui bagaimana pandangan masyarakat di kabupaten ini mengenai wacana pajak lingkungan yang ditujukan untuk melindungi kondisi lingkungan tempat mereka tinggal.

\section{TINJAUAN PUSTAKA}

Fungsi Pajak

Pemerintah memungut pajak dengan berbagai alasan dan fungsinya. Pajak berfungsi sebagai sumber utama penerimaan negara (budgetary), alat pengatur (regulatory), alat penjaga stabilitas dan sebagai sarana redistribusi pendapatan (Wahyutomo, 1994; Chidir, 1993).

Pajak berfungsi sebagai budgetair adalah fungsi pajak yang dipergunakan sebagai alat atau instrumen untuk memasukkan dana secara optimal ke kas negara (Wahyutomo, 1994; Chidir, 1993).

Pajak juga berfungsi sebagai alat pengatur atau regulator. Fungsi ini menjadikan pajak sebagai instrumen untuk mencapai tujuan tertentu yang sesuai dengan rencana dan keinginan pemerintah (Pudyatmoko, 2002).

Selain fungsi budgetair dan fungsi regulator, pajak juga mempunyai fungsi sebagai alat penjaga stabilitas (Fidel, 2008:3). Artinya pajak berfungsi sebagai pengatur pertumbuhan ekonomi dan menjaga stabilitas perekonomian.

Dan yang tak kalah pentingnya adalah pajak berfungsi sebagai sarana redistribusi pendapatan (Fidel, 2008:3).

Fungsi dan Jenis Pajak Lingkungan 
Menurut Haryadi (2006) selaku Wakil Ketua Umum Kadin Bidang Kebijakan Publik, Perpajakan, dan Sistem Fiskal menyatakan fungsi utama dari pajak lingkungan adalah sebagai regulator karena pajak lingkungan digunakan untuk mencapai suatu tujuan tertentu sesuai rencana pemerintah.

Menurut European Environment Agency (EEA, 2000), menyatakan bahwa "environmental taxes classified according to their point of application are usually levied on polluting activities." Artinya, pajak lingkungan dapat diklasifikasikan menurut jenis polutan di suatu lingkungan. Contohnya pajak atas jumlah polutan dalam air limbah (misalnya Biochemical Oxygen Demand (BOD), Chemical Oxygen Demand (COD)) dan polusi udara (sulphur dioxide $\left(\mathrm{SO}_{2}\right)$, oxides of nitrogen $\left(\mathrm{NO}_{\mathrm{x}}\right)$ ). Pajak lingkungan juga dapat diklasifikasikan menurut bidang operasi, meliputi pajak energi, pajak transportasi (seperti pajak atas kendaraan) dan pajak atas polusi dan sumber daya alam non - energi (seperti pajak atas emisi, produk non - energi, bahan baku dan limbah).

Terkait dengan jenis-jenis dari pajak lingkungan, pajak lingkungan merupakan jenis pajak yang baru di Indonesia. Pajak lingkungan di Indonesia bisa berupa pajak yang dipungut oleh pemerintah pusat maupun daerah dan bisa juga merupakan pengembangan dari jenis pajak-pajak yang sudah ada (Haryadi, 2006).

Masalah Lingkungan di Kabupaten Kepulauan Siau Tagulandang Biaro (Sitaro).

Kabupaten Kepulauan Siau Tagulandang Biaro (Sitaro) merupakan salah satu kabupaten kecil yang berada di Provinsi Sulawesi Utara. Keberadaannya pun tidak banyak orang yang mengetahuinya. Kabupaten ini menjadi objek penelitian ini untuk memperkenalkan ke masyarakat Indonesia bahwa terdapat pulau kecil yang memiliki beberapa keunggulan yang sepatutnya diketahui, diantaranya dari sektor pariwisata, banyak sekali objek wisata yang dapat dikunjungi seperti keindahan panorama bawah laut / terumbu karang.

Selain sektor pariwisata, pastinya sektor pertanian/perkebunan, seperti pala, kelapa, dan cengkih. Sektor perikanan juga tidak kalah dari sektor yang lainnya di kabupaten ini.

Dengan beberapa keunggulan yang ada, tentunya adapula kelemahan yang mendampingi di kabupaten ini terutama di masalah lingkungan. Pada Kabupaten Kepulauan Siau Tagulandang Biaro ini, industri berkapasitas besar masih dibilang kurang, tetapi masyarakat cukup terganggu dengan hal tersebut.

Menurut Jhon Kardo sebagai Kepala Seksi Pemilihan Lingkungan Hidup di Kabupaten Kepulauan Sitaro, terdapat satu perusahaan yang bergerak di bidang aspal yang cukup mengganggu lingkungan.

Kemudian masalah listrik juga cukup mengganggu lingkungan, karena di kabupaten ini listrik yang digunakan masih berasal dari Pusat Listrik Tenaga Diesel (PLTD) 
belum dari PLN sehingga pada prosesnya, juga asap pembuangan gasnya keluar melalui corong yang mengakibatkan udara sekitar Kabupaten Kepulauan Sitaro ini tercemar.

Menurut surat kabar dari suara sitaro, Dra Mey Welang menyatakan resiko pencemaran lingkungan akibat merambahnya usaha perbengkelan di Kepulauan Siau kian hari meningkat. Karena para pengusaha atau pemilik bengkel tersebut masih saja membuang Bahan Beracun Berbahaya (B3) di sembarang tempat seperti oli bekas (Suarasitaronews, 2014)

Dari beberapa kasus yang telah terjadi di Kabupaten Kepulauan Siau Tagulandang Biaro ini dapat menjadi bukti bahwa kasus pencemaran lingkungan menjadi isu yang penting di daerah ini.

Melihat keadaan bahwa kondisi keseimbangan alam di Indonesia semakin menurun dan kebijakan pajak lingkungan ditolak penerapannya, maka studi tentang kebijakan pajak lingkungan tetap harus dilaksanakan demi tersedianya dana khusus untuk konservasi lingkungan.

Untuk itu, studi ini mengambil topik mengenai persepsi masyarakat umum, para pelaku bisnis kecil, serta pemerintah terhadap wacana pajak lingkungan. Studi ini dapat mendukung agar isu ini tetap bergulir di masyarakat sehingga pemerintah dapat mempertimbangkan lagi kebijakan mengenai pajak lingkungan. Subjek studi adalah di Kabupaten Kepulauan Siau Tagulandang Biaro (Sitaro) yang merupakan kepulauan terpencil tapi menyimpan potensi kerusakan alam.

\section{METODE PENELITIAN}

Penelitian ini menggunakan pendekatan kualitatif dimana Kabupaten Kepulauan Siau Tagulandang Biaro (Sitaro) yang menjadi obyek penelitian. Jenis data yang digunakan dalam penelitian ini adalah data kualitatif dengan sumber data yang digunakan adalah data primer yang diperoleh melalui hasil wawancara dan data sekunder yang diperoleh melalui bahan kepustakaan.

Prosedur pengumpulan data dilakukan dengan dua cara yakni dengan penelitian kepustakaan yang terdiri dari peraturan perundang-undangan yang terkait dengan perpajakan, lingkungan hidup, maupun yang terkait dengan pajak lingkungan itu sendiri, disertai pula dari buku, artikel dari koran dan arsip atau data yang dipublikasikan oleh pemerintah dan dengan penelitian lapangan.

Penelitian lapangan akan dilakukan dengan dua cara yaitu wawancara dan dokumentasi. Wawancara dilakukan dengan pihak-pihak yang terkait yaitu pemerintah, para pelaku bisnis yang tergabung dalam Ikatan Kecil Menengah dan masyarakat umum.

Informan diperoleh dengan menggunakan teknik snowball sampling dimana teknik penentuan sampel yang mula-mula jumlahnya kecil kemudian membesar. Total 
responden dalam penelitian ini adalah 40 orang. Terdapat beberapa pertanyaan yang diajukan dalam wawancara sebagai pedoman dalam penelitian ini.

Untuk dokumentasi berupa laporan atau peraturan yang diterbitkan oleh pemerintah Provinsi Sulawesi Utara.

Teknik analisa data dalam penelitian ini menggunakan model analisis interaktif, yaitu data yang dikumpulkan akan dianalisa melalui tiga tahap yaitu reduksi data, menyajikan data dan menarik kesimpulan (Sutop, 2002).

Dalam penelitian ini yang dilakukan untuk pengujian keabsahan data ialah dengan teknik triangulasi (Emzir, 2010). Pengecekan derajat kepercayaan dilakukan melalui mekanisme pengumpulan data sesuai dengan yang disampaikan dalam prosedur pengumpulan data.

\section{HASIL PENELITIAN DAN ANALISA}

Kesadaran Terhadap Pajak Lingkungan

Tingkat kesadaran baik pemerintah, para pelaku bisnis kecil, dan masyarakat umum di Kepulauan Sitaro ini lebih banyak mengarah kepada belum menyadari adanya isu pajak lingkungan di Indonesia. Terlihat jelas dari berbagai jawaban dan alasan yang diberikan atas adanya penerapan pajak lingkungan di Indonesia.

Menurut hasil survei wawancara dengan kalangan pemerintahan yakni oleh Ibu Chany D. Frans sebagai Kepala Bidang Perindustrian di Kabupaten Kepulauan Siau Tagulandang Biaro (Sitaro), beliau menyatakan bahwa "Iya saya menyadari karena itu sangat penting untuk pengembangan Indonesia ke depan." ${ }^{1}$

Maksud beliau tersebut, dengan adanya pajak lingkungan pastinya pengembangan Indonesia ke depan bisa menjadi lebih baik, tidak hanya pajak lingkungan ini berperan untuk lingkungan saja, melainkan dengan adanya pajak tersebut berarti ada tambahan pendapatan yang akan diperoleh pemerintah untuk mengelola pendapatan tersebut sesuai dengan tujuan dan kebutuhannya.

Perbedaan respon dinyatakan oleh salah satu responden dari kalangan masyarakat umum yang tinggal di Kabupaten Kepulauan Siau Tagulandang Biaro (Sitaro) yakni oleh Bapak Leonardo Ponto bahwa "Kalau sampai saat ini belum menyadari adek dan belum tau adanya penerapan pajak lingkungan di Indonesia." ${ }^{2}$ Dengan adanya pengakuan dari Bapak Leonardo Ponto ini setidaknya dari kalangan masyarakat umum juga dapat dikatakan masih kurang kesadarannya terhadap pajak lingkungan di Indonesia.

Tingkat kesadaran baik dari pemerintah daerah, kalangan pelaku bisnis yang tergabung dalam Ikatan Kecil Menengah/IKM, dan masyarakat umum di Kabupaten Kepulauan Sitaro ini memang masih dikatakan kurang, karena kebanyakan belum menyadari akan

\footnotetext{
${ }^{1}$ Hasil Wawancara dengan Ibu Chany D. Frans, Kepala Bidang Perindustrian, Kabupaten Kepulauan Sitaro.

${ }^{2}$ Hasil Wawancara dengan Bapak Leonardo Ponto, Masyarakat Umum, Kabupaten Kepulauan Sitaro. 
adanya penerapan pajak lingkungan ini yang disebabkan karena kurangnya informasi dan pemahaman mengenai pajak lingkungan.

\section{Usulan Bentuk Kebijakan Pajak Lingkungan}

Empat responden yang diwawancarai dari pihak pemerintah memberikan tanggapan yang sama, yaitu setuju terhadap penerapan pajak lingkungan di Indonesia. Pernyataan tersebut sesuai dengan salah satu responden dari pihak pemerintah, yang dikatakan oleh Bapak Nanggolansisi yang menjabat sebagai Kepala Seksi Pemilihan Kehutanan dan Lingkungan Hidup yang menyatakan bahwa "Sangat setuju dengan adanya penerapan pajak lingkungan tersebut, melihat bagaimana pentingnya lingkungan untuk masyarakat terutama di Kabupaten ini." 3

Alasanpun diutarakan oleh beliau untuk setuju dengan penerapan pajak lingkungan, yaitu "Karena sejauh ini lingkungan berperan sekali terhadap kehidupan masyarakat kalau lingkungan itu dirusak untuk memperbaharui lingkungan itu kita ambil dananya darimana? Jadi dengan adanya pajak ini kita doronglah pajak yang dikasih ini kita buat untuk mengembalikan kerusakan lingkungan yang diakibatkan oleh perusahaan tersebut." 3

Hasil wawancara dengan Bapak Nanggolansisi yang menjabat sebagai Kepala Seksi Pemilihan Kehutanan dan Lingkungan Hidup, beliau memberikan pandangan bahwa "Pajak lingkungan ini hendaknya harus diterapkan seefektif mungkin, dan dipergunakan sebaik-baiknya kalau boleh dipakai grade (tingkatan) kalau sumber daya diambil banyak ya pasti dia berbanding lurus dengan kerusakan yang ditimbulkan, jadi kita hitung saja dari situ, kan kita boleh menghitung pajak dari situ sumber daya alam yang dipakai dan dari situ dikenakan pajaknya, tapi pajaknya ini kita buat untuk memperbaharui lingkungan kita spesifik aja jadi kalau boleh seperti itu." ${ }^{4}$

Beberapa pandangan diatas merupakan tanggapan dari pihak pemerintah selaku pengambil kebijakan yang berada di Kabupaten Kepulauan Sitaro yang nantinya dapat menjadi acuan untuk pemerintah pusat dalam memperkenalkan pajak lingkungan sebagai kebijakan yang baru di masa yang akan datang.

Untuk pihak kalangan para pelaku bisnis Ikatan Kecil Menengah (IKM), dari total 15 responden, seluruhnya memberikan tanggapan setuju dengan diterapkannya pajak lingkungan di Indonesia. Hasil wawancara yang dilakukan terhadap salah satu pebisnis IKM yaitu pada IKM Akelabo dengan pemiliknya yang bernama Ibu Tamaka, bisnis usaha pembuatan roti memberikan pernyataan bahwa "Ya, sekali lagi saya sampaikan saya

\footnotetext{
${ }^{3}$ Hasil Wawancara dengan Bapak Nanggolansisi, Kepala Seksi Pemilihan Kehutanan dan Lingkungan Hidup, Kabupaten Kepulauan Sitaro.

${ }^{4}$ Hasil Wawancara dengan Bapak Nanggolansisi, Kepala Seksi Pemilihan Kehutanan dan Lingkungan Hidup, Kabupaten Kepulauan Sitaro.
} 
sangat setuju agar kita menjaga lingkungan kita dengan baik, tidak sengaja, artinya dalam hal ini kita selalu hati-hati dan selalu memperhatikan kelestarian lingkungan." ${ }^{5}$ Tentunya dengan respon yang positif terhadap adanya penerapan pajak lingkungan, adapula pandangan atau harapan dari para pebisnis IKM terhadap dampak yang mungkin terjadi dari penerapan pajak lingkungan.

Berbagai pendapat yang dilontarkan kalangan pebisnis untuk saran yang diperlukan, seperti salah satunya yaitu Bapak Daniel Takaendengang yang merupakan pemilik IKM Tanaki dengan usaha keripik ubi menyatakan "Kalau saran saya untuk pembebanan pajak ini kita lihat usaha-usaha, ketika usahanya dia besar ya untuk pembebanan pajak mungkin disesuaikan dengan besaran usaha itu, dan juga mungkin sesuai dengan besaran limbah yang dihasilkan dari usaha itu." ${ }^{6}$

Dari pandangan, saran dan harapan yang diungkapkan oleh pihak pemerintah, para pelaku bisnis IKM dan masyarakat umum di Kabupaten Kepulauan Sitaro dapat disimpulkan ada tiga area yang harus diperhatikan oleh pemerintah pusat jika akan menerapakan pajak lingkungan. Tiga area tersebut adalah proses pembentukan kebijakan pajak lingkungan, pengenaan dasar tarif pajak lingkungan dan pengelolaan hasil pajak lingkungan.

Pembentukan kebijakan pajak lingkungan harus melibatkan pihak DPR, DPRD, DPD, masyarakat bisnis baik besar maupun kecil dan pemerintah. Pengenaan dasar tarif pajak lingkungan dapat ditentukan berdasarkan jumlah sumber daya alam yang diambil, jumlah total asset yang dimiliki, jumlah limbah yang dihasilkan dan kadar limbah beracun yang dihasilkan.

Sedangkan harapan yang diungkapkan oleh masyarakat umum dan para pelaku bisnis IKM atas pengelolaan hasil pajak lingkungan adalah supaya pajak lingkungan dapat menjadi alat preventif terhadap kerusakan lingkungan.

\section{Pandangan Terhadap Tujuan Pajak Lingkungan}

Pandangan terhadap pajak lingkungan merupakan suatu hal yang penting untuk mendukung efektifitas dalam penerapan pajak lingkungan di masa yang akan datang. Semua reponden kalangan pemerintah sepakat bahwa tujuan dari pajak lingkungan untuk perlindungan lingkungan. Salah satunya adalah Bapak Jhon Kardo Nanggolansisi selaku Kepala Seksi Pemilihan Kehutanan dan Lingkungan Hidup menyatakan bahwa

\footnotetext{
${ }^{5}$ Hasil Wawancara dengan Ibu Tamaka, IKM Akelabo, Kabupaten Kepulauan Sitaro.

${ }^{6}$ Hasil Wawancara dengan Bapak Daniel Takaendengang, IKM Tanaki, Kabupaten Kepulauan Sitaro. 
"Diharapkan tujuannya untuk kelestarian lingkungan dan memberikan manfaat yang besar bagi lingkungan kita."7

Tanggapan masyarakat umum pun tidak berbeda jauh dengan kalangan pelaku bisnis IKM dan pemerintah. Dilihat dari tujuan pajak lingkungan, dari 21 responden yang mewakili masyarakat, 12 responden dari masyarakat umum memandang bahwa tujuan pajak lingkungan secara umum digunakan untuk kepentingan lingkungan.

Seperti saat mewawancarai Bapak R. Kadisi menyatakan bahwa "Agar supaya pertama dengan adanya pajak lingkungan, lingkungan tidak semakin minim untuk dicemari terlebih untuk orang-orang yang kurang kesadaran." 8

Sedangkan lima responden lainnya memandang bahwa pajak lingkungan berguna untuk meningkatkan pendapatan pemerintah dan tidak hanya untuk lingkungan saja. Salah satunya oleh Ibu Yunita Komaling, beliau menyatakan bahwa "Sejauh mana yang saya tau tentang pajak itu merupakan suatu pendapatan, jadi mulai pajak itu ada pendapatan dari daerah itu mungkin, atau di negara itu sendiri."

Hasil wawancara dengan responden dari kalangan pemerintah, pelaku bisnis IKM dan masyarakat umum menyimpulkan bahwa tujuan pajak lingkungan adalah pertama untuk kepentingan dalam melindungi lingkungan dari pencemaran dan yang kedua adalah untuk meningkatkan pendapatan pemerintah.

Dari hasil penelitian ini juga dapat disimpulkan bahwa pajak lingkungan dapat berfungsi sebagai fungsi budgetair dan regulator. Fungsi budgetair adalah untuk kepentingan pemerintah dalam meningkatkan pendapatan dan fungsi regulator sebagai alat untuk membentuk suatu perilaku yang peduli akan kebersihan lingkungan.

\section{Yuridiksi Wewenang Pemungut Pajak Lingkungan}

Hasil wawancara dengan responden dari pemerintah mendapatkan pandangan repsonden terhadap yurisdiksi wewenang pemungut pajak lingkungan. Kebijakan pajak lingkungan dapat dimasukkan ke dalam Undang-Undang Pajak Daerah dan Retribusi Daerah atau dibuatkan Undang-Undang Pajak Lingkungan tersendiri.

Dari empat responden yang mewakili pihak pemerintah, tiga responden menyatakan bahwa pajak lingkungan lebih baik masuk ke dalam kewenanagan pemerintah daerah sebagai pemungut. Hal ini diungkapkan oleh salah satu responden yaitu Bapak Jhon Kardo Nanggolansisi sebagai Kepala Seksi Pemilihan Kehutanan dan Lingkungan Hidup bahwa "Karena kita di daerah alangkah lebih jelas atau bagusnya dalam bentuk UndangUndang Pajak dan Retribusi Daerah dalam daerah kita karena kan yang berdiri perusahaan di daerah kita sehingga nantinya masukan tersebut untuk memperbaharui

\footnotetext{
${ }^{7}$ Hasil Wawancara dengan Bapak Nanggolansisi, Kepala Seksi Pemilihan Kehutanan dan Lingkungan Hidup, Kabupaten Kepulauan Sitaro.

${ }^{8}$ Hasil Wawancara dengan Bapak R. Kadisi, Masyarakat Umum, Kabupaten Kepulauan Sitaro.

${ }^{9}$ Hasil Wawancara dengan Ibu Yunita Komaling, Masyarakat Umum, Kabupaten Kepulauan Sitaro.
} 
lingkungan di daerah kita masing-masing." ${ }^{10}$ Dengan adanya pendapat dari beliau, karena langsung tepat pada daerah masing-masing sehingga kontribusinya lebih kelihatan dan dapat langsung digunakan untuk kepentingan lingkungan di daerah itu tanpa harus melalui proses yang panjang.

Namun satu responden yaitu Bapak Jostanlie De Son Bogar sebagai Sekretaris DPRD Kabupaten Kepulauan Sitaro, beliau menyatakan bahwa "Undang-Undang Pajak Lingkungan tersendiri, alasan karena lingkungan terpisah, sehingga lingkungan merupakan hal yang kompleks disitu."11 Dari tanggapan yang berbeda ini, beliau lebih mengharapkan pajak lingkungan dapat menjadi Undang-Undang tersendiri karena lingkungan ini cakupannya bisa luas, sehingga alangkah baiknya apabila terpisah dari hal yang lain sehingga benar-benar terfokuskan hanya pada lingkungan tidak dengan yang lainnya.

\section{Visibilitas Pajak Lingkungan}

Hasil wawancara dengan pihak pelaku bisnis IKM memberikan pandangan bagaimana visibilitas penerapan pajak lingkungan di daerah Kabupaten Kepulauan Sitaro. Bagi mereka secara keseluruhan mereka setuju terhadap penerapan pajak lingkungan asal kebijakan tersebut dapat diterapkan secara adil dalam membebani biaya pajak tambahan terhadap pelaku bisnis kecil dan masyarakat umum.

Hal ini diungkapkan oleh Bapak Corneles Baweleng, pemilik dari IKM Paseng dengan usahanya tanah liat dan tempurung menyatakan bahwa "Sudah tepat, tetapi dengan catatan dimana pajak pembayaran yang harus dikeluarkan pemerintah untuk pengusaha dalam hal nantinya pengenaan pajak lingkungannya harus dihitung secara tepat ada tidaknya limbah yang berasal dari perusahaan tersebut sehingga dapat adil juga dalam penerapannya." ${ }^{12}$

Pendapat dari Bapak Corneles ini beliau memang menyatakan sudah tepat, tetapi alangkah baiknya apabila pemerintah sebagai pengambil kebijakan tidak hanya memperhatikan pengenaan pembayaran pajak lingkungan saja, harus juga dapat mengawasi atau mengontrol ke lapangan sudah sesuai perusahaan tersebut harus bertanggungjawab atas limbah yang dikeluarkan atau sebaliknya.

Tiga responden dari pihak para pelaku bisnis IKM menyatakan ketidaksetujuannya terhadap tambahan biaya pajak lingkungan ini. Seperti salah satunya diungkapkan oleh Bapak Hendrik Abram selaku pemilik IKM Tatahadeng dengan usahanya yaitu meubel

\footnotetext{
${ }^{10}$ Hasil Wawancara dengan Bapak Nanggolansisi, Kepala Seksi Pemilihan Kehutanan dan Lingkungan Hidup, Kabupaten Kepulauan Sitaro.

${ }^{11}$ Hasil Wawancara dengan Bapak Jostanlie De Son Bogar, Sekretaris DPRD Kabupaten Kepulauan Sitaro.

${ }^{12}$ Hasil Wawancara dengan Bapak Corneles Baweleng, Masyarakat Umum, Kabupaten Kepulauan Sitaro. 
menyatakan bahwa "Kalau menurut saya, saya tidak setuju penerapan pajak lingkungan, karena menambah biaya pajak yang saya bayar selama ini, karena usaha IKM ini usaha yang bermodal sedikit dan menghasilkan laba yang sedikit pula katakanlah pas-pasan digunakan untuk makan sehari-hari dan biaya anak sekolah." ${ }^{13}$ Tentunya, untuk suatu perusahaan industri yang besar membiayai pajak lingkungan bukan merupakan beban yang terlalu berat karena memang industrinya juga mengeluarkan limbah berbahaya untuk lingkungan.

Berbeda halnya dengan usaha Ikatan Kecil Menengah (IKM) ini, para pelaku bisnis ini merasa tidak mengeluarkan limbah berbahaya hanya kebanyakan limbah rumah tangga yang tidak berbahaya, kemudian dengan pendapatan yang tidak terlalu banyak akan merasa lebih keberatan untuk menanggung biaya pajak lingkungan sehingga diharapkan lebih proposional dan adil.

\section{Kebutuhan Kepulauan Sitaro Terhadap Pajak Lingkungan}

Daerah Kabupaten Kepulauan Sitaro saat ini masih tidak begitu mendapat dampak buruk terhadap pencemaran lingkungan tersebut karena kurangnya perusahaan besar yang ada di Kabupaten ini. Namun tumbuhnya ekonomi di kabupaten ini membawa banyak perusahaan baik besar maupun kecil untuk menjalankan bisnis mereka di kabupaten ini. Hasil wawancara dengan Ibu Joice Kumaat selaku Kepala Bidang Pajak dan Retribusi DPPKMD menyatakan bahwa tidak hanya dari PLN saja, beliau memberikan pendapatnya yaitu "Di Sitaro ini, limbah dari rumah sakit, PLN, dan bengkel-bengkel karena kalau industri belum terlalu berkembang di Sitaro ini." ${ }^{14}$ Tetapi limbah yang paling mengganggu yang banyak dinyatakan oleh responden di kalangan pemerintah ini yaitu limbah dari asap aspal.

Pihak pelaku bisnis IKM juga berpendapat bahwa pencemaran lingkungan belum menjadi problem akut di kabupaten ini karena mereka mampu mendaur ulang limbah yang dihasilkan oleh produksi mereka. Contohnya, Ibu Ellen Pumpente yang merupakan pemiliki IKM Blessing, beliau menyatakan bahwa "limbahnya kan kita disini usahanya meubel jadi bikin-bikin kursi, bikin-bikin sofa, nah lebih-lebihnya artinya sisa-sisanya dari kayu bisa dipergunakan sebagai bahan bakar dan kalau bikin sofa kalau misalnya ada potongan-potongan busa yang lebih kita biasanya buatkan bantal-bantal untuk sofa dan sisa-sisa kainnya yang lain kita masukin ke jok biar dia tidak menimbulkan limbah atau tidak mengotori lingkungan gitu." 15

Tingkat pencemaran di daerah Kabupaten Kepulauan Sitaro yang dirasakan oleh masyarakat umum adalah pencemaran udara dari PLN, pabrik aspal dan kendaraan

\footnotetext{
${ }^{13}$ Hasil Wawancara dengan Bapak Hendrik Abram, IKM Tatahadeng, Kabupaten Kepulauan Sitaro.

${ }^{14}$ Hasil Wawancara dengan Ibu Joice Kumaat, Kepala Bidang Pajak dan Retribusi DPPKMD, Kabupaten Kepulauan Sitaro.

${ }^{15}$ Hasil Wawancara dengan Ibu Ellen Pumpente, IKM Blessing, Kabupaten Kepulauan Sitaro.
} 
bermotor. Masyarakat umum disini lebih banyak memikirkan lingkungan yang ditempati bebas dari polusi karena apabila bebas dari polusi tentunya kesehatan para masyarakat umum pun terjamin.

\section{KESIMPULAN}

Dari wawancara dengan pemerintah, para pelaku bisnis IKM dan masyarakat umum diketahui bahwa Kabupaten Kepulauan Sitaro yang merupakan daerah terpencil saja sudah membutuhkan adanya pajak lingkungan karena udara disana sudah tercemar.

Masalah lingkungan dan kebijakan apa yang diambil oleh pemerintah meruapakan masalah yang kompleks. Jika pajak lingkungan diterapkan kemungkinan besarnya adalah beban masyarakat akan semakin tinggi. Pajak lingkungan juga harus bersikap adil bagi usaha besar dan kecil dan usaha yang menghasilkan limbah bahaya dan tidak berbahaya.

\section{DAFTAR PUSTAKA}

Abdullah, Syukriy. 2009. Pajak Daerah dan Retribusi Daerah Dalam RUU PDRD. http://syukriy.wordpress.com/2009/08/08/pajak-daerah-dan-retribusidaerah-dalam-ruu-pdrd/, diakses 7 Juli 2014.

Chidir, Ali. ASH. 1993. Hukum Pajak Elementer. Bandung: PT. Eresco.

Dresner, S., et. al. 2006a. Social and Political Responses to Ecological Tax Reform in Europe : An Introduction To The Special Issue. Journal of Energy Policy 34 : 895-904.

2006b. History and Social Responses to Environmental Tax Reform In The United Kingdom. Journal of Energy Policy 34 : 930-939.

European Environment Agency. 2000. Environmental Taxes: Recent Developments in Tools for Integration. http://reports.eea.eu.int/Environmental Issues No 18/en, 7 Juli 2014.

Emzir. 2010. Metode Penelitian Kualitatif Analisis Data. Jakarta:Rajawali Pers.

Fidel. 2008. Pajak Penghasilan. Jakarta: Carofin Publishing.

Hardjasoemantri, Koesnadi. 2005. Hukum Tata Lingkungan. Gajah Mada University Press:Yogyakarta.

Haryadi. 2006. Pemerintah Ngotot Pajak Lingkungan Masuk RUU Pajak dan Retribusi Daerah. $\quad$ http://www.hukumonline.com/berita/baca/hol14900/pemerintahngotot-pajak-lingkungan-masuk- diakses tanggal 7 Juli 2014. 
Hasan, D., \& Dinarjati, E.P. 2008. Tinjauan Terhadap Rencana Penerapan Pajak Lingkungan Sebagai Instrumen Lingkungan Hidup di Indonesia. Universitas Gadjah Mada Yogyakarta.

Kumurur, Veronica. 2006. Pencemaran Perairan Teluk Buyat, Sulawesi Utara Indonesia. http://veronicakumurur.blogspot.com/2006/08/oleh-veronica-kumurur-kasusbuyat.html, diakses 8 Agustus 2014.

Makmun. 2009. Badan Kebijakan Fiskal : Green Taxes Versus Green Insentive. http://www.fiskal.depkeu.go.id/webbkf/kolom/detailkolom.asp?NewsID=N1403 $\underline{01017}$, diakses 9 Juli 2014.

Pudyatmoko, Y. Sri. 2002. Pengantar Hukum Pajak. Yogyakarta: PT. Andi.

Suarasitaronews. 2014. Awas!! B3 Bisa Mencemarkan Lingkungan. http://www.suarasitaronews.com/2014/04/awas-b3-bisa-mencemarkanlingkungan.html, diakses tanggal 9 November 2014.

Sutop,HB. 2002. Metode Penelitian Kualitatif Dasar Teori dan Terapannya dalam Penelitian. Surakarta:Universitas Sebelas Maret.

Undang-Undang Republik Indonesia Nomor 4 Tahun 1984 sebagaimana telah diubah terakhir dalam Undang-Undang Republik Indonesia Nomer 32 Tahun 2009 tentang Perlindungan dan Pengelolaan Lingkungan Hidup.

Wahyutomo, Imam. 1994. Pajak. Yogyakarta: UPP AMP YKPN. 